\title{
Innovation in Curriculum: An Overview
}

\author{
Robert S. Fox/University of Michigan
}

Innovation in curriculum is gaining its thrust from a new set of value priorities-humanism, concern for racial and socioeconomic minorities, support of pluralism and diversity, increased interest in affective development, education for the very young, and legitimization of the search for value. These priorities are coupled with new understandings of how learning takes place, which cast the learner in an active, responsible, self-actualizing role and, at the same time, support the development of precise, highly organized sets of learning materials designed to achieve clearly defined objectives as efficiently as possible. Implications of these factors are examined in relation to curriculum design, instructional materials, professional roles, and the need for in-service education.

L'innovation des programmes d'étude est activée par une nouvelle échelle de priorités des valeurs: esprit d'humanisme, intérêt manifesté à l'égard des minorités raciales et socio-économiques, appui accordé au pluralisme et à la diversité, intérêt accru envers le développement affectif, éducation des très jeunes, et légitimisation de la recherche des valeurs. Ces priorités vont de pair avec de nouvelles connaissances sur le processus d'acquisition du savoir, connaissances qui lancent l'élève dans un rôle actif et responsable dans son épanouissement personnel et qui, en même temps, contribuent à la mise au point d'une série de textes éducatifs précis et hautement organisés conçus en vue de la poursuite, d'une manière aussi efficace que possible, de certains objectifs clairement définis. L'auteur étudie les répercussions provoquées par ces facteurs sur la conception des programmes, les textes d'étude, les rôles professionnels et la nécessité d'une éducation en cours d'exercice.
Even a cursory review of the new curriculum materials packages and programs exhibited at recent national conferences of the Association for Supervision and Curriculum Development brings into startling focus the major expansion of curriculum resource materials now available for teachers and students. While these materials do not in themselves document the extent of innovation and change in the curriculum in all its aspects, they do intrigue one to discover what is happening in the school curriculum field that parallels the rapid changes in other dimensions of the society.

\section{Defining Curriculum}

First, it may be helpful to delimit the field. Curriculum, for the purposes of this discussion, is the plan for learning - the framework, strategies, and materials designed to support and give direction to the learning transaction.

A diagram of some of the elements in the educational process helps to make clear this delineation. Figure 1 shows three major elements-the curriculum, the learning transaction, and the support system. Teachers and students draw from the curriculum support for the creation of learning activities. The learning transaction is profoundly influenced by the teacher's values and attitudes, competencies and skills, teaching purposes, commitments, etc., and by the students' corresponding sets of values and attitudes, purposes, home and racial backgrounds, motivations, etc. The framework, strategies, and materials provided by the curriculum to support and give direction to the learning transaction may or may not be effectively used, carefully followed, or creatively modified. They may be rejected altogether. Nevertheless the curriculum remains that set of plans and support materials. The learning activities that result from a dynamic process of interaction may be quite different from those envisioned by the plan.

In examining curriculum innovation, we are concerned with innovations having to do with each of the categories of the process diagrammed in Figure 1: values, purposes, curriculum sources, curriculum design, teaching methodology, curriculum materials, and curriculum utilization.

\section{New Value Priorities}

It is hard to apply the term innovative to a set of values. Many of the values that underlie the educational program are enduring. It may be more a question of which 


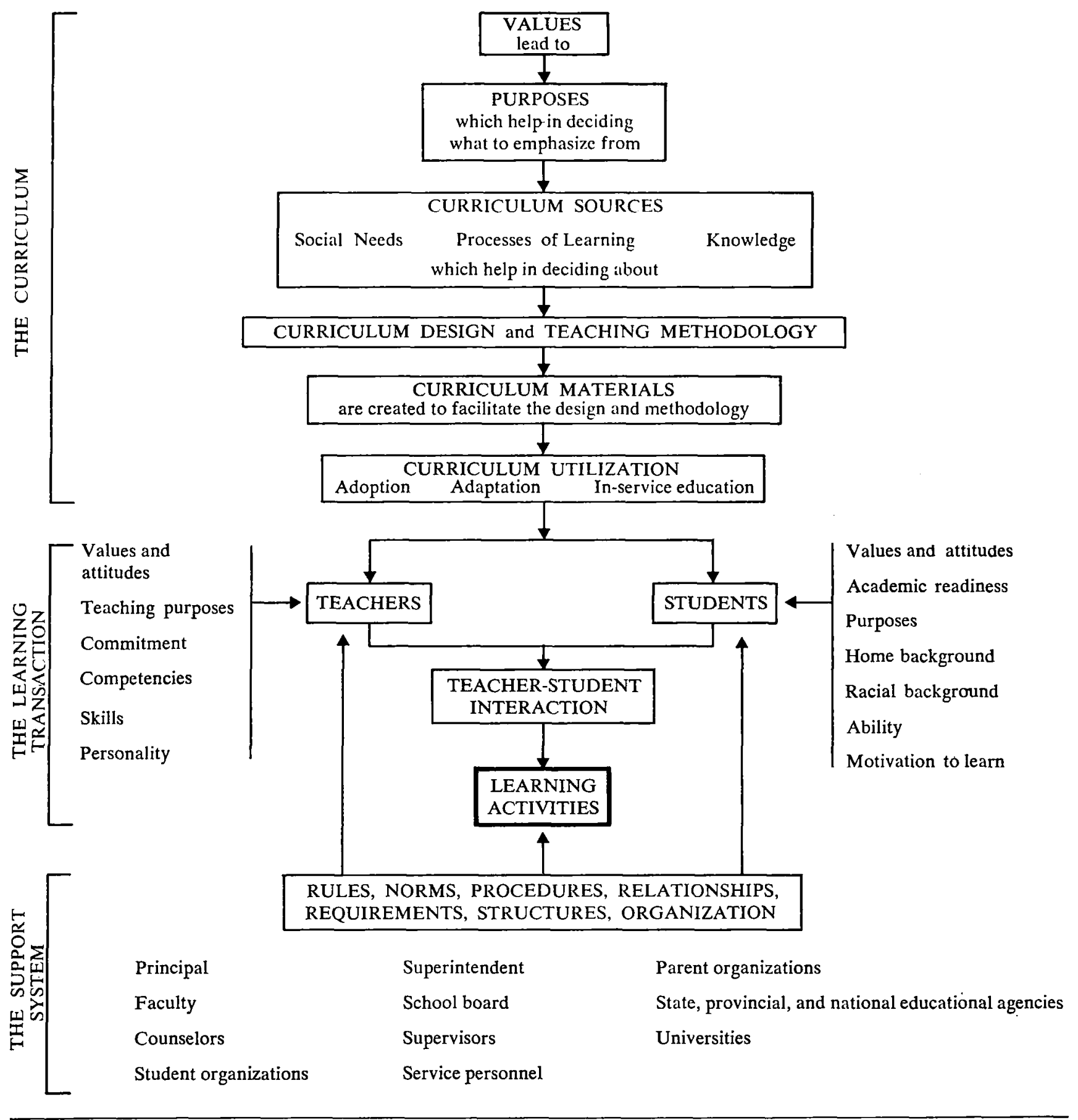


of the enduring values are in the ascendency at a particular time, rather than what new values have entered the picture. However, there are new value clusters moving into the ascendency at this time, and they are affecting curriculum decisions. Schools may be marked as innovative to the extent that they reflect some of these new priorities.

We discuss briefly six of these new value priorities: emphasis on humanism, equality of educational opportunity in relation to racial and socioeconomic minorities, pluralism, the "whole" child, education for the very young, and the search for value or relevance itself.

Humanism. Perhaps it is the new student and teacher activism that is pushing the idea that schools are for people; that the school is an interacting community of students, teachers, administrators, clerks, custodians, and parents. "School climate" has become important (Fox, 1971; Fox \& Lippitt, 1969). Questions of involvement in decision-making, power and influence, openness of communication, interpersonal support, clarity of roles, rewards, and sanctions have taken priority over lesson plans, textbook adoptions, attendance regulations, and homework assignments.

And yet the new humanistic emphasis is not unchallenged. There are some who would define objectives more precisely and behaviorally, would tailor the instructional activities toward these objectives, and reward learners for their step-by-step progress toward these clearly defined ends. As Goodlad (1969) puts it, "Behaviorism and rediscovered and reinterpreted humanism are rubbing against each other more abrasively. Is an embryonic revolution in the hitherto rather sleepy field of curriculum about to be born of the social revolution of our time?" (p.371). Yet it is clear that schools are moving toward giving greater attention to the humanistic values, and curriculum programs and materials are responding to this new priority.

Equality of educational opportunity. With the Supreme Court's decision of 1954 declaring segregated schools unconstitutional, the term equality of educational opportunity began to take on a new urgency. Riots in the inner cities gave emphasis to the need for improved conditions of life for the poor and disenfranchised. Much of the expression of this concern is focused on providing the conditions for learning-finances, integrated classrooms and school buildings, teachers and administrative staffs who are more representative of the minority groups, consolidation of schools in rural districts. But priorities for curricular change are also being altered: textbooks are being screened for the adequacy of their treatment of minority groups, materials are being developed in the "black dialect," compensatory programs are being created to correct deficiencies in the educational background of some children. The value of providing an excellent education to all youth is in the ascendency.

Pluralism. In a sense, American education has always valued pluralism through its emphasis on local community responsibility for schools. A great variety of approaches to schooling has been permitted to develop. Yet, have the approaches been so different? The pressures toward conformity and toward standardization have been both subtle and direct. While we have not had a nationally controlled school system, there has been amazing similarity in curricular offerings across the nation. Within school systems, the trend has been much more to decide on the one best way to do it and then require all schools and classrooms to conform, than it has been to encourage diversity, multiple paths to the goal, and even pluralistic goals. As schools in the United States performed their "melting pot" function, the commonalities within the cultural heritage were stressed rather than the diversities. In Canada, cultural pluralism has always been a valued part of the culture. However, as new life styles become more acceptable in the larger society, schools are permitted a wider latitude in examining the underlying values and implications of these ideas.

The current valuing of pluralism is reflected not only in the increasing variety of programs and activities being made available to the student-increased electives, mini-courses, individualized study programs, richly varied instructional materials - but in a more basic willingness to recognize and support basic differences in belief systems. The curriculum provides for "value inquiry" rather than straightforward indoctrination in a set of "American" or "Canadian" values. A school permits some classrooms to be "open" while others are more structured. Alternative schools are being created and supported even within the regular school system.

The "whole" child. Of the several value priorities described so far, emphasis on the "whole" child seems less innovative, more a recycling of an old view after 
a Sputnik-induced period of concern for the subjectmatter disciplines. Yet, as with the focus on humanism, there is a new dimension. The affective domain is being recognized as important, nay vital, in the lives of adolescent youth and adults as much as it has been for any children in the primary grades. Thanks to Bloom et al. (1956) and Krathwohl, Bloom, and Masia (1964), affective objectives have been given equal billing with the cognitive, and even the psychomotor realm is legitimized. Feelings and attitudes are the dynamic partners of facts and concepts, and thus deserve thoughtful and planned attention from the designers of curriculum (Biber, 1972).

Education for the very young. In the past, education of the so-called "preschooler," the child from infancy to six years of age, was seen as peripheral to the main task of public education. Preschool education was a frill, a special benefit to those who could afford it, like ballet lessons or horseback riding. Now the evidence is becoming clear that these early years may be the most formative, and the most important educationally. Bloom (1964), after analyzing approximately 1000 longitudinal studies of early learning, concluded that changes in the development of human characteristics become more difficult with increasing age. These studies may be responsible for much of the recent heavy emphasis upon developing curriculum and instructional techniques for very young children (McNeil, 1969), and for the high value now being placed on early childhood education (no longer "preschool").

The search for value. Finally, an emerging value priority appears to be legitimization of the search for value itself. In this the youth are in the vanguard. As Wilson (1972) puts it in his defense of the openaccess curriculum:

"One of the most obvious and persistent characteristics of American youth in the 1970s is their restless and unpredictable striving for some kind of existential truth. Ultimately, their concerns are 'moral' but they are asking their questions in different and unfamiliar ways. ... One expects the young, who have the largest stake in the future, to be in the vanguard of value redefinition." (p.44)

We are coming to recognize that there is a pluralism of values as well as need for a pluralism of learning opportunities. As youth search for value, and question some of the assumed values of their elders, the school has an opportunity to encourage and support value inquiry and dialogue, rather than react with defensiveness and indoctrination.

"Curriculum planners can commit time and space, allocate financial resources, and recruit teaching personnel to support a never-ending dialogue of academic specialties concerned with human values. They can teach the relationship of knowledge to thoughtful decision making. They can structure learning experiences in such a way that the non-logical, intuitive response of current existential thought is not summarily ruled out. They can introduce students to theoretical constructs that are change-oriented but still not so painfully relativistic that decisions are limited to complete withdrawal or violent confrontation." (p.45)

\section{The Refocusing of Purposes}

Innovation in curriculum is a response to the priorities set by the values that have been given priority, and to the purposes for education derived from these values. The purposes of public education are in the process of being refocused. During the past two decades there seemed to be fairly general agreement around the major objectives (Educational Policies Commission, 1938; French, 1957). School was seen as the place to learn to be a responsible citizen, to learn how to make a living, and to gain certain of the skills and knowledge that would contribute to one's richness of living through self-realization and human relationships. Schools were also seen as an agent of social purpose as they served to build a common set of values and appreciation for the national heritage. More recently, they contributed to the national need for scientists and technical specialists by emphasizing science, mathematics, and languages.

Reimer (1970) takes a more caustic, and perhaps more realistic, view of those purposes that characterize most of our schools. He sees schools in all nations performing four basic functions: custodial care, socialrole selection, indoctrination, and education. Regretfully, he points out that the first three functions often absorb most of the resources, leaving little for true education. While these purposes may not enjoy the professional and public acclaim the Educational Policies Commission statement was accorded, they nonetheless appear to be tacitly accepted. 
Support for innovation through a refocusing of purpose is taking place, however. Some of these purposes include self-actualization, positive self-esteem, value clarification, management of change, and development of instrumental skills.

Helping the student become a self-actualizing individual is becoming much more the focus of school programs than characterized the dependency-creating programs of the past (Bremer \& von Moschzisker, 1971; Maslow, 1961; Zahorik \& Brubaker, 1972). Students are being given opportunities to make more decisions about their own learning, to take initiative in utilizing the educational resources of the school, and to share in the governance of that school. The shift seems to be toward Dewey's concept of the educated man as one who has gained the capacity to continue his own learning, and away from the criterion of subject-matter mastery for its own sake.

Schools are becoming more concerned with supporting the development of positive self-esteem in children and youth (Association for Supervision and Curriculum Development, 1962). Given the relationship of self-esteem to academic achievement and other forms of learning, the development of positive selfesteem is seen as instrumental to the realization of the learning goals of the school, as well as being of obvious inherent worth on its own merits.

Helping the learner to develop and clarify his own values and to use them in making decisions about his life and life in the community around him forms another purpose for the educational program, which is coming into sharper focus (Raths, Harmin, \& Simon, 1966). How teachers can retool to support this process becomes a target for innovative effort, as well as the development of curriculum materials and programs to support value inquiry and clarification.

The fact that students are growing up in a world that is rapidly changing has been recognized as having profound impact on the learner and on what he learns. Only recently, however, has it become a major purpose of education to help the learner cope with change, to manage himself effectively within the changing conditions, and to take some initiative in directing the course of change (Mead, 1971; Van Til, 1971). John Garner's concept of the "self-renewing" individual sets the model. Specific goals might deal with helping the child gain the skills of making new friends easily when his family moves to a new community; seeking a variety of alternatives rather than just one, before deciding on a course of action; gaining skill in using values in guiding one's actions.

These examples of refocused purposes would not be representative if they failed to include the continued emphasis on the academic skills-but skills seen as instrumental to continued learning and not ends in themselves. Reading, writing, and arithmetic are joined by the skills of the scientist, the humanist, and the artist -data collection and analysis, creative expression of ideas, identifying and using resources, applying the lessons from past experience to present problems. The tools help the student to seek and discover knowledge for himself rather than to remain dependent on the teacher or the educational system.

\section{Curriculum Sources}

What's new with regard to curriculum sources is not so much that the major sources-the needs of the society, the learning process, the nature and content of the subject-matter disciplines-have been replaced, but that particular things within each of these important areas are now being emphasized. From the psychological foundations for curriculum, some are choosing to emphasize the gestalt - the big picture - in which the learner is an inquirer, a problem-solver, an activist. A major role of the teacher is seen as setting the environment for learning, developing a climate within which learning is motivated, supported, rewarded (Association for Supervision and Curriculum Development, 1970; Bruner, 1963). Curriculum materials are the resources, the raw materials from which the learner draws his data for subsequent analysis. Generalizations are developed inductively, based on increasingly sophisticated inquiry efforts.

There is another group that is drawing upon the psychological foundations for theory and research, which focuses on the relationship between the stimulus and the response, the instructional "program" and the resultant behavior on the part of the learner. This neo-behaviorism deals in behavioral objectives, small sequential steps within the larger learning task, programming, and the control of rewards through contingency management (Engelmann, 1971; Gagné, 1970; Lumsdane \& Glaser, 1960). While it is true that those who have become enthusiastic about behavior modification often choose to focus on those parts of the total curriculum that lend themselves best to analysis, specification, and manipulation, they also seek to benefit the whole of curriculum by encouraging greater 
clarity and specificity of goal statements, identifying goal indicators, and pushing for the specification of more precise outcomes that can be measured.

These two differing points of emphasis are probably not incompatible. While some curriculum innovators have focused on the uniqueness of one or the other approach, extolling its virtues and promoting the materials that support that approach, the truth is that there are different kinds of learning tasks. An active, inquiring learner is compatible with the new value focus on humanism, pluralism, and the promotion of value inquiry. Curriculum materials and methods need to support this active, inquiry stance. At the same time the active learner may also be well served by having available to him carefully organized and sequenced learning materials so that he is supported in the efficient achievement of such specific objectives as learning a new mathematical skill or understanding a new concept in social studies. The crucial factor may be that the student be involved in the decision about what is to be learned and when, leaving the matter of what is the most efficient way of learning it to be determined in part by the nature of the learning task.

The use of schools as an instrument of social policy continues to be one of the major ways in which curriculum responds to the needs of the society. Currently in focus are the political-social priorities of providing equality of opportunity for minority groups-particularly blacks, but including Chicanos, American Indians, and women - and the elimination of poverty and the effects of deprivation. Although some object to placing on the schools the burden of achieving integration, while housing patterns, employment opportunities, and many other aspects of social life are not as vigorously modified, it is clear that schools are being askedeven mandated-into major program modifications toward these social goals. While the techniques of forced bussing, redrawing of attendance lines, and large campus school complexes are being used to modify patterns of student contact, they have little chance of success without program modification. Innovative curriculum materials and programs are appearing in response to this need. Pressure is being placed on textbook authors and publishers to provide a fair, accurate, and balanced treatment of minority groups (Rosenberg, 1972). Black studies programs are being introduced. Basic sociological and psychological concepts are being incorporated in social studies programs designed to address human relationship prob- lems, including racism (e.g., the unit "Discovering Differences" for Grades 4 to 6-Lippitt, Fox, and Schaible, 1969).

The attack on poverty has been pushed in the school setting through a wide variety of programs, many focused on providing compensatory educational experiences for disadvantaged children. Project Head Start provided readiness experiences to the preschool child from disadvantaged homes. Project FollowThrough supports an exciting group of "models" for innovative curriculum modification in kindergarten through Grade 3 for the disadvantaged child (Maccoby \& Zellner, 1970).

The sources of curriculum modification that stem from the subject-matter disciplines are not in the ascendency at the moment. Yet any examination of curriculum innovation in the early 1970 s would discover products of a major effort during the ' $60 \mathrm{~s}$ by most of the disciplines to update and redirect the school curriculum in their particular subject-matter fields. Starting with the Physical Science Study Committee (PSSC), which introduced dramatic new methodology into the teaching of physics as well as providing a new content, each of the other major discipline groups undertook curriculum revision projects--the biologists, earth scientists, mathematicians, anthropologists, sociologists, economists, etc. (for one listing of such projects, see Taylor and Groom, 1971).

Examination of the inherent characteristics of each discipline and the relationships among them has produced guidelines for the structure of curriculum programs. The idea is that "if students discover how one body of knowledge succeeds another, if they are aware of the substantive structures that underlie current knowledge, if they are given a little freedom to speculate on the possible changes in structure which the future may bring, they will not only be prepared to meet future revisions with intelligence but will also better understand the knowledge they are currently being taught" (Schwab, 1964).

Gagné (1970) has pushed particularly hard on the importance of identifying the basic concepts within a discipline and arranging them in a teaching sequence so that each concept is taught after an adequate structure of prerequisite concepts has been laid.

\section{Curriculum Design Factors}

The implications of Gagnés theory and research for curriculum design are clear. The question must be 
asked, "What must a student know so that he can acquire new knowledge?" Working backwards, one arrives at the simplest or most basic elements and starts building the curriculum there. Design becomes highly important if learning is to be supported efficiently.

The programmed-learning people develop a tight design, at least for certain learning sequences, from necessity. The organization of learning into a series of small steps, each of which can be successfully completed, reinforced, and used in understanding the next step, requires a carefully worked out design. Through a pragmatic item analysis, those sequences that work are retained; those that do not work are replaced.

These points make a lot of sense to those concerned with fixing accountability for instruction. If learning goals can be specified clearly and subdivided into detailed components, and instruction be sequenced so that the specified objectives are dealt with in a systematic manner, then the effectiveness of the teaching process can be measured. This factor is appealing to those administrators who are accountable to the public for effective expenditure of tax dollars. Thus, in the state of Michigan, the Superintendent of Public Instruction has launched a state-wide program of identifying minimal behavioral objectives for each subject area and each grade level of the curriculum (Michigan Dept. of Education, 1971). As these are eventually determined, they will become in a sense a state-wide curriculum design. Not only will this design guide the content and sequencing of learning activities throughout the state, but it will be used in the preparation of evaluation instruments so that the effectiveness of instructional programs may be judged.

However, not all feel that it is appropriate to structure the curriculum so tightly. McNeil (1969, p. 309 ) indicates that "not all instructional objectives have sequentially dependent 'learning sets' through which the student must proceed to reach successively more complex kinds of competence." He cites research by Mager and McCann (1963) as demonstrating the superiority of learners who controlled the instructional sequence for certain training tasks. They also report that learners' motivation increased with the amount of control the learners were allowed to exercise over the learning sequence.

Thus, we have emerging, on the one hand, curriculum materials and programs that are tightly designed and are almost "teacher proof" in the sense that they place great value on maintaining the planned sequence of a set of detailed learning tasks, all directed toward the achievement of agreed-upon objectives. On the other hand, there are curriculum programs that are extending the options available to the learner. More electives are permitted. There are fewer prerequisites and an increased variety of "mini-courses," which permit the learner to engage in an exploration of his special interests. Curriculum materials developed for such learning activities are inclined to be along the lines of "building blocks" or raw materials, which learner and teacher can assemble into a useful pattern as the design of the learning activity evolves.

In general, it would appear that curriculum designs that permit more control by the learner are most compatible with the value priorities identified at the beginning of this paper. It is quite possible, however, that the learner will be aided in exercising this responsibility by having available learning designs and materials that clearly lay forth the objectives toward which they are directed, and in which the proposed learning activities bear an obvious relationship to the objectives. These factors will make it possible for the learner, and the teacher in support of the learner, to make choices that are goal relevant.

Implications of these new approaches to curriculum design can be drawn for the roles of teachers, students, and parents. Instead of assuming that the main responsibility for design of the program rests with the experts -the curriculum developer, the subject-matter specialist, the psychologist-it is clear that the users need to be involved. The learners, together with their parents and teachers, need to have enough understanding of the principles of curriculum design so that they can make wise choices regarding the selection of components, the sequencing of learning activities, and the creative development of new learning activities when needed. Techniques such as the Curriculum Materials Analysis System (CMAS) designed by the Social Science Education Consortium in Boulder, Colorado, illustrate the ways teachers are being helped in meeting this challenge.

\section{Curriculum Innovation and Teaching Methodology}

The new curricula demand new skills from teachers. The need has been recognized from the inception of the PSSC program in physics. Built into the implementation plan was a requirement that teachers attend a summer workshop for instruction in how to use the methodology of the new curriculum. In spite of this 
stringent requirement, research evidence shows that most physics teachers who attempted the new program failed to modify their traditional methodologies to a significant degree (Trowbridge, 1960).

The Biological Sciences Curriculum Study (BSCS) programs as well as PSSC stressed the teacher understanding of the nature of scientific inquiry rather than the teaching of scientific information. Innovative programs in the social sciences also concerned themselves with inquiry processes and deplored the lack of adequate in-service education materials and programs to help teachers utilize the programs effectively. The National Science Foundation, in recognition of the need, has sponsored for a number of years summer and academic-year institutes for experienced teachers in the various physical, biological, and social science disciplines for which new curriculum programs have been developed. Reports are that these institutes generally have emphasized the up-dating of subject-matter knowledge but have failed to help the teacher become competent in using the newer methodologies (Fox, Girault, Lippitt, \& Schaible, 1967). Examples of specific concern involved in the new methodologies include procedures for involving students in the raising of inquiry questions, grouping procedures and the management of small-group work, conducting value inquiry, data collection procedures, utilization of resources, analysis procedures, generalizing, techniques for raising a class to higher levels of thinking, and support of individual inquiry activities.

As the variety of sophisticated instructional materials increases, the teacher is confronted with a major methodological problem. He must devise ways of gaining access to the material that is uniquely appropriate for each particular learner or learner group at the time it is needed, and he must devise a classroom management scheme so that these students or student groups can engage in the kind of learning activity that the material is designed to support. Both logistical and teaching skills are required. It is quite possible that one of the major innovations in teaching methodology that the new curriculum resources will bring about will be an extension of the team-teaching concept-a division of labor around some of the technological, management, and teaching functions that are required.

The new methodologies also underwrite the need for the provision of continuing in-service education opportunities for the teacher (Fox et al., 1967). Curriculum developers and publishers find themselves giving attention to the provision of teacher-support materials that go beyond the usual teacher guides. Local school districts are assuming increased responsibility for in-service education and new roles, such as Director of Staff Development or Coordinator of InService Education, are being added to the central administrative staff of school systems. In some schools the in-service education function is being dealt with by creating a new role for one of the teachers in each building.

\section{Innovative Curriculum Materials}

At one time curriculum materials were considered to be the curriculum. The textbook, or the course of study, was assumed to reflect all that was needed to support the learning transaction. This paper's definition of curriculum clearly extends the concept to include many other kinds of processes. Some of these are, of course, reflected in written materials-statements of purpose, charts showing relationships between various aspects of the program, teachers' guides, in-service teacher education materials, tests and other evaluative devices, as well as instructional materials for direct use with the learners. Yet, the full "plan for learning-the framework, strategies, and materials designed to support and give direction to the learning transaction"-also has dimensions that are unwritten: expectations of parents or of the school administration; teacher skill in using various methodologies, informal lesson plans, plans that evolve from teacher-student interaction or from individual learner designing of his specific inquiry activity. Yet the materials are important. And they are increasingly innovative.

One obvious characteristic of modern instructional materials is that they are multimedia. They are printed, visual, and audio, often all packaged together into one set of resources. They include cassette tape libraries, filmstrips, overhead transparencies, $8 \mathrm{~mm}$ single-concept motion-picture films, kits of material for laboratory experiments, microfiche cards, recording and playback devices, games, simulation activities, artifacts, project books, and computer "software." Required for efficient use of such materials is an extensive array of equipment: Cassette tape recorder, overhead projector, motion-picture projector, record player, typewriter, microfiche reader, and computer terminal. Often the program requires these devices to be hooked up together, so that the tape recording can accompany a filmstrip or the computer terminal be 
used with a project book or motion picture.

A second characteristic of most of these innovative curriculum materials is that they are designed to support individualized instruction. They lend themselves to student self-use. Often they are organized and/or packaged in such a way as to make possible studentinitiated learning. That is, the particular instructional goal-the skill or concept toward which the material is directed-is made clear so that the student (or students) can select the appropriate set of materials himself as the need develops, without being dependent on a teacher's intervention.

A third characteristic is the opportunity that many of the newer instructional materials provide for active student involvement. Thus, rather than being based on the assumption that most learning takes place by organizing and presenting knowledge to the learner in convenient packages, most of the innovative materials support inquiry, stimulate question-raising, provide search materials, or set up situations in which newly learned knowledge or skill can be tested and applied.

Finally, the kinds of supportive materials available to the teacher and students are for the most part based on the assumption that there will be a dynamic and creative learning process and that teacher and learners will be continuously engaged in planning, designing, modifying, and implementing a variety of learning activities. Therefore, the materials are flexible; they lend themselves to adaptation; they are conceived of as building-blocks, not as the complete structure.

The availability of such a variety of instructional materials and learning resources is resulting in the creation of a new supporting role within the school building and the school system-that of curriculum materials specialist. By assisting the teacher in retrieving and in drawing implications or making applications to the particular teaching or learning problems being confronted at the moment, the curriculum materials specialist assumes a more active role than the school librarian of old. He becomes an integral part of the instructional team.

\section{Curriculum Utilization}

Effective utilization of the product of all the described effort is, of course, the goal of the curriculum development process. For those concerned with bringing about urgently needed changes in the educational program, utilization is conceived as the final step in the process. Such terms as adoption, installation, and implementa- tion reflect this conception. Study of processes of change in education (Havelock, 1971) are yielding a greater understanding of how change efforts conceived by specialists (researchers, theorists, developers, and so forth) can be efficiently brought to fruition in the classroom.

Some of this concern has been a reaction to the rather naive assumption of the $1930 \mathrm{~s}$, ' $40 \mathrm{~s}$, and ' $50 \mathrm{~s}$ that the key to curriculum improvement was the classroom teacher. Since the teacher, competent professional that he was, could judge best the nature of the educational needs of the group of learners trusted to his care, and was in the best position to develop a realistic plan for meeting these needs, he and his colleagues were charged with building the curriculum. Teacher curriculum committees struggled to determine goals, identify essential content, develop scope and sequence designs, and describe methodologies. They wrote teachers' guides, resource units, and student materials. The ditto machine was used extensively, and curriculum libraries sprung up so that these homemade materials could be shared with other school systems.

About the time of Sputnik, specialists in the various disciplines concerned with upgrading the national capacity to cope with rapidly changing technological demands being placed on our society looked at our educational programs and were appalled at the lack of correspondence between the current state of knowledge in their fields and what was being taught in schools. The result of this concern has been a major reorientation of the curriculum development process from reliance on the practitioner in the local school setting to substantial utilization of expert resources from the scientific and the larger educational community.

All has not gone well, however. Excellent new programs have not brought about the major improvements their creators had envisioned. Some teachers failed to follow instructions in the manual. Others seemed not to have their hearts in it. Parents puzzled about the changes and sometimes opposed them. Some schools embarked enthusiastically on major program changes, then abandoned them to try still newer programs.

One constructive response to these difficulties has been to pay more attention to the installation problem and become more sophisticated in managing this aspect of the change process. The excellent discussion by Mahan in this issue of Interchange provides an analysis of this problem and describes possibilities for improving the process. 
What the situation calls for, however, is more than attending to improving the efficiency of adoption of an innovation by the school system. It calls for a meaningful combination of a procedure for utilizing the wealth of resources from the entire scientific and educational communities throughout the nation with a dynamic and motivating problem-solving process engaged in by the faculty, students, and parents of the local school building. This process has been best described by Jung and Lippitt (1966) as a "research utilization problemsolving model." It holds that the core of a curriculum improvement process is the involvement of a staff (or a subgroup, or individual teacher) in a problem-solving process (Figure 2). Thus, the school group engages in goal setting, in documenting the discrepancy between these goals and the current state of affairs, in defining the need for change, in setting specific objectives, and in seeking a variety of alternative ways of moving toward these objectives. The problem-solving activity continues through the selection of one of the alternatives to try out. The tryout process is monitored, and the results evaluated. Decisions are made about necessary modifications, and whether or not to extend the use of the innovation.

None of this problem-solving effort occurs in a vacuum, however. Resources are actively sought and utilized at every stage of the process. Decisions are made regarding the relevance of resources for the purposes toward which the local group is working. The problem-solving group decides whether a curriculum package available from a prominent publisher has something to offer, given the needs, objectives, and particular situation in the school. Data are sought from the local school setting that help in clarifying the problem, or in identifying obstacles that need to be overcome.

The model is based on the assumption that no local group can possibly deal effectively with the challenge of needed curriculum improvement by relying solely on its own resources. Now, as never before in history, the school can draw upon the best expertise available in the nation. Through division of labor and mass production, creative ideas and the supporting materials for implementing such ideas can become available at modest cost to the consumers. Yet, such resources are meaningful only to the extent that they tie into an ongoing problem-solving process engaged in by those who are responsible for carrying the program through to its conclusion.

\section{Summary}

We have seen that innovation in curriculum is gaining its thrust from a new set of value priorities-humanism, a concern for improved educational opportunity for racial and socioeconomic minorities, a willingness to support pluralism and diversity, an increased interest in the affective as well as the physical and intellectual development of the child, education for the very young, and the legitimization of the search for value.

These value priorities are leading to a refocusing of purposes. Innovative curricula are concerned with supporting self-actualization and a positive self-esteem in the learner. They are directed toward helping the learner develop and clarify his values. They focus on ways to assist the learner in coping with and managing change. They support the development of skills that are instrumental to further learning and effective problem-solving.

New understandings of how learning takes place move the new curricula toward casting the learner in an active, responsible, self-actualizing role and, at the same time, support the development of some precise, highly organized sets of learning materials designed to achieve clearly defined objectives as efficiently as possible. This seemingly compatible dichotomy is one reason for the expansion of the teaching-team concept with differentiated competencies and tasks. There need to be teachers skilled in the management of inquiry processes and problem-solving activities; there is also need for technicians and managers of the processes of individual study, programmed and computerassisted instruction, record keepers, and persons who can organize, retrieve, and assist with the use of a wide variety of learning materials.

Curriculum design is providing more sophisticated sequences of learning activities or modules, while at the same time facilitating branching, variation, and individual student adaptation. More options are being provided. These innovations are matched by new teaching methodologies, which include procedures for involving students in the raising of inquiry questions; grouping procedures and the management of smallgroup work; conducting value inquiry; supporting students in the collection of data; utilizing a wide variety of resources; analyzing, generalizing, and applying what is learned in action situations; techniques for raising a class to higher levels of thinking; and supporting individual inquiry activities.

In some respects curriculum innovation is seen 
Figure 2/Curriculum Improvement through Problem-Solving

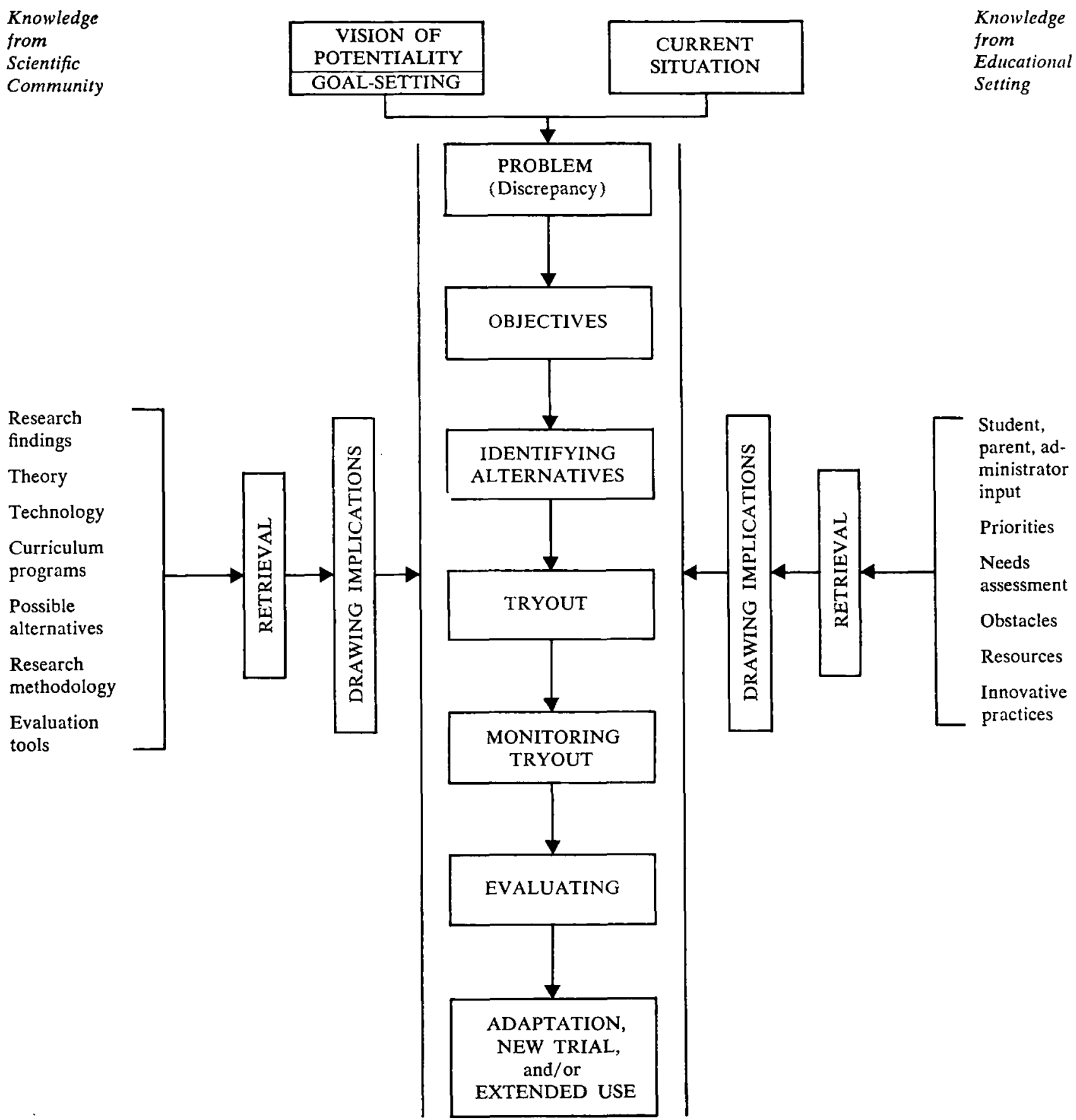


most visibly in the form of new instructional materials -multimedia, variable in format, appealing to different learning styles, directed toward the support of a great variety of teaching-learning activities: they form a resource never before available.

All these innovations are making increasingly urgent the need for continuous in-service professional growth opportunities for the teacher, opportunities to learn about and gain skill in the use of such new methodologies and materials.

The effective utilization of these new programs and materials is seen increasingly as dependent upon a process that involves teachers in the local school in an active problem-solving effort.

\section{References}

Association for Supervision and Curriculum Development. The positive view of self. In Perceiving, behaving, becoming. Washington, D.C.: The Association, 1962. Pp.99-117.

Association for Supervision and Curriculum Development. To nurture humaneness: Commitment for the '70s. Washington, D.C: The Association, 1970.

Biber, B. The "whole" child. Individuality, and values in education. A new look at progressive education. Washington, D.C.: Association for Supervision and Curriculum Development, 1972. Pp.44-87.

Bloom, B. S. Stability and change in human characteristics. New York: Wiley, 1964.

Bloom, B. S., et al. (Eds.) Taxonomy of educational objectives. Handbook I: Cognitive domain. New York: McKay, 1956.

Bremer, J., \& von Moschzisker, M. The school without walls. New York: Holt, Rinehart \& Winston, 1971.

Bruner, J. The process of education. Cambridge, Mass.: Harvard University Press, 1963.

Educational Policies Commission. The purposes of education in American democracy. Washington, D.C.: National Education Association, 1938.
Engelmann, S. Preventing failure in the primary grades. Chicago: Science Research Associates, 1971.

Fox, R., Brainard, E., Howard, G., Georgiday, W., \& Olivero, J. The principal as the school's climate leader: $\boldsymbol{A}$ new role for the principalship. Englewood, Colo.: CFK, 1971.

Fox, R. S., Girault, E., Lippitt, R., \& Schaible, L. Inservice education to support the utilization of new social science curricula. Boulder, Colo.: Social Science Education Consortium, 1967.

Fox, R. S., \& Lippitt, R. The human relations school. Englewood, Colo.: CFK, 1969.

French, W. Behavioral goals of general education in high school. New York: Russell Sage Foundation, 1957.

Gagné, R. M. The conditions of learning. New York: Holt, Rinehart \& Winston, 1970.

Goodlad, J. I. Curriculum: State of the field. Review of Educational Research, 1969, 39, 367-375.

Havelock, R. G. Planning for innovation through dissemination and utilization of knowledge. Ann Arbor, Mich.: Center for Research on Utilization of Scientific Knowledge, 1971.

Jung, C., \& Lippitt, R. The study of change as a concept. Theory into Practice, 1966, 5,

Krathwohl, D. R., Bloom, B. S., \& Masia, B. B. Taxonomy of educational objectives. Handbook II: Affective domain. New York: McKay, 1964.

Lippitt, R., Fox, R., \& Schaible, L. Discovering differences. Social Science Laboratory Units. Chicago: Science Research Associates, 1969. (a)

Lippitt, R., Fox, R., \& Schaible, L. The teacher's role in social science investigation. Chicago: Science Research Associates, 1969. (b)

Lumsdane, A., \& Glaser, R. Teaching machines and programmed learning: $A$ source book. Washington, D.C.: Dept. of Audio-Visual Instruction, National Education Association, 1960.

Maccoby, E., \& Zellner, M. Experiments in primary education: Aspects of Project Follow-Through. New York: Harcourt, Brace, Jovanovich, 1970.

Mager, R. F., \& McCann, J. Learner-controlled instruction. Palo Alto, Calif.: Varian, 1963.

Maslow, A. H. Some basic propositions of a growth and self-actualization psychology. In Perceiving, behaving, becoming. Washington, D.C.: Association for Supervision and Curriculum Development, 1962. Pp.34-49.

McNeil, J. D. Forces influencing curriculum. Review of Educational Research, 1969, 39, 293-318. 
Mead, M. Youth revolt: The future is now. In W. Van Til (Ed.), Curriculum: Quest for relevance. Boston: Houghton Mifflin, 1971. Pp.234-241.

Michigan Dept. of Education. The common goals of Michigan education. Lansing: The Department, 1971.

Raths, L., Harmin, M., \& Simon, S. B. Values and teaching. Columbus, O.: Merrill, 1966.

Reimer, E. An essay on alternatives in education. Interchange, 1970, 2(1), 1-35.

Rosenberg, M. Criteria for evaluating the treatment of minority groups in textbooks and other curriculum materials. A Michigan Association for Supervision and Curriculum Development Position Paper, 1972. (Obtainable from Virginia Sorenson, President, Grand Rapids Area Office, WMU, 105 N. Division, Grand Rapids, Mich. 49502.)

Schwab, J. J. Structure of the disciplines: Meanings and significances. In G. W. Ford \& L. Pugno (Eds.), The structure of knowledge and the curriculum. Chicago: McNally, 1964. Pp.6-30.

Taylor, R. L., \& Groom, T. L. Social studies education projects: An ASCD index. Washington, D.C.: Association for Supervision and Curriculum Development, 1971.

Trowbridge, L. M. An analysis of the objectives and materials of the Physical Science Study Committee course in high school physics. Unpublished doctoral dissertation, University of Michigan, 1960.

Van Til, W. Curriculum: Quest for relevance. Part III. Curriculum for the future. Boston: Houghton Mifflin, 1971. Pp.219-269.

Wilson, L. C. The open access curriculum. Boston: Allyn \& Bacon, 1971.

Zahorik, J. A., \& Brubaker, D. Toward more humanistic instruction. Dubuque, Iowa: Brown, 1972. 